\title{
THE PHILOSOPHY OF MR. B*RTR*ND R*SS*LL.
}

[Some further fragments found in a Prayer Book of Free Man's Worshipl rescued with a few of the late $\mathrm{Mr}$. R*ss*ll's belongings; see The Monist, Vol. XXI, October, 1911, pp. 483-508. The abbreviations used in the present instalment are as follows:

A. A. W. Lewis Carroll, Alice's Adventures in Wonderland, London, Macmillan, 1905. People's edition.

T. L. G. Lewis Carroll, Through the Looking-Glass, and What Alice Found There, London, Macmillan, 1915. People's edition.

H. S. Lewis Carroll, The Hunting of the Snark: an Agony in Eight Fits, London, 1911.

E. N. Richard Dedekind, Essays on the Theory of Numbers, Chicago and London, 1901.

P. E. Bertrand Russell, Philosophical Essays, London and New York, 1910.

Pr. M. Bertrand Russell, The Principles of Mathematics, Vol. I, Cambridge, University Press, 1903.

P. M. Alfred North Whitehead and Bertrand Russell, Principia Mathematica, Vol. I, Cambridge, 1910.

P. P. Bertrand Russell, The Problems of Philosophy, London and New York, 1912.

M. The Monist: a Quarterly Magazine Devoted to Science and Philosophy, Chicago and London.]

THE TERM "LAWS OF THOUGHT."

People often assume that laws of logic are laws of thought. ${ }^{2}$ Perhaps the most frequent instance is the treatment of an identity as if its validity were a matter of our permission. Some people suggest to others that they should "let bygones be bygones."

1 This apparently refers to the Essay on "The Free Man's Worship" on pp. 59-70 of the Philosophical Essays (London, 1910) of Mr. B*rtr*nd R*ss*1l's distinguished contemporary, Mr. Bertrand Russell, from whom Mr. R*ss*ll's philosophy was derived.

2 Cf. P.P., pp. 113, 136. 


\section{OBJECTIVE VALIDITY OF THE LAWS OF THOUGHT.}

$I$ once inquired of a maid-servant whether her mistress was at home. She replied, in a doubtful fashion, that she thought that her mistress was in unless she was out. I concluded that the maid was uncertain as to the objective validity of the law of the excluded middle, and remarked this to her mistress. Her mistress seemed to imagine that I wished to impute to the maid some moral defect of an unimportant nature, and remonstrated with me in an amused way. The mistress probably imagined that I meant to find fault with the maid's capacity for thinking, as I used the phrase "law of thought," and perhaps committed the common mistake of supposing that a "law of thought" has something to do with thinking.

\section{CRITICISM.}

Those people who think that it is more godlike to seem to turn water into wine than to seem to turn wine into water surprise me. I cannot imagine an intolerable critic. It seems to me that, if $A$ resents $B$ 's criticism in trying to put his (A's) discovery in the right or wrong place, $A$ acts as if he thought he had some private property in truth. The White Queen seems to have shared the popular misconception as to the nature of criticism. ${ }^{3}$

\section{THE PRAGMATIST THEORY OF TRUTH.}

The pragmatist theory that "truth" is a belief which works well sometimes conflicts with common sense and not with logic. It is commonly supposed that it is always better to be sometimes right than to be never right. But this is by no means true. For example, consider the case of a watch which has stopped; it is exactly right twice every day. A watch, on the other hand, which is always five minutes slow is never exactly right. And yet there can be

${ }^{3}$ See Appendix A, below. 
no question but that a belief in the accuracy of the watch which was never right would, on the whole, produce better results than such a belief in the one which had altogether stopped. The pragmatist would, then, conclude that the watch which was always inaccurate gave truer results than the one which was sometimes accurate. In this conclusion the pragmatist would seem to be correct, and this is an instance of how the false premises of pragmatism may give rise to true conclusions.

From the text written above the church clock in a certain English village: "Be ye ready, for ye know not the time," we would conclude that the clock never stopped for a period as long as twelve hours. For the text is a rather vague symbolical expression of a propositional function which is asserted to be true at all instants. The proposition that a (presumably intelligent) observer of the clock at any definite instant does not know the time, implies, then, that the clock is always wrong. Now if the clock stopped for twelve hours it would be absolutely right at least once. It might be right twice if it were right at the first instant it stopped or the last instant at which it went; but the second possibility is excluded by hypothesis, and the occurrence of the first possibility-or of the analogous possibility of the stopped clock being right three times in twenty-four hours-does not affect the present question. Hence the clock can never stop for twelve hours.

The pragmatist's criterion of truth appears to be far more difficult to apply than the Bellman's ${ }^{5}$ that what he said three times is true, and to give results just as insecure.

THE SYNTHETIC NATURE OF DEDUCTION.

Doubt has often been expressed as to whether a syllogism can add to our knowledge in any way. J. S. Mill and

1 Both cases cannot occur; the question is similar to that arising in a discussion of what is meant by saying "Socrates is mortal," see below.

See Appendix B, below. 
H. Poincare in particular held the opinion that the conclusion of a syllogism is an "analytic" judgment in the sense of Kant, and therefore could be obtained by the mere dissection of the premises. Any one, then, who maintains that mathematics is founded solely on logical principles, would appear to maintain that mathematics, in the last instance, reduces to a huge tautology.

John Stuart Mill, in Chapter III of Book II of his System of Logic, said that "it must be granted that in every syllogism, considered as an argument to prove the conclusion, there is a petitio principii. When we say

\section{All men are mortal, \\ Socrates is a man, therefore \\ Socrates is mortal,}

it is unanswerably urged by the adversaries of the syllogistic theory, that the proposition, Socrates is mortal, is presupposed in the more general assumption, All men are mortal; that we cannot be assured of the mortality of all men unless we are already certain of the mortality of every individual man; that if it be still doubtful whether Socrates, or any other individual we choose to name, be mortal or not, the same degree of uncertainty must hang over the assertion, All men are mortal; that the general principle, instead of being given as evidence of the particular case, cannot itself be taken for true without exception until every shadow of doubt which could affect any case comprised with it is dispelled by evidence aliunde; and then what remains for the syllogism to prove? That, in short, no reasoning from general to particular can, as such, prove anything, since from a general principle we cannot infer any particulars but those which the principle itself assumes as known. This doctrine appears to me irrefragable...." 
"It is," says Mr. Russell, "an old debate among philosophers whether deduction ever gives new knowledge. We can now see that in certain cases at least it does do so. If we already know that two and two always make four, and that Brown and Jones are two, and so are Robinson and Smith, we can deduce that Brown and Jones and Robinson and Smith are four. This is new knowledge, not contained in our premises, because the general proposition, 'two and two are four,' never told us there were such people as Brown and Jones and Robinson and Smith, and the particular premises did not tell us that there were four of them, whereas the particular proposition deduced does tell us both these things. But the newness of the knowledge is much less certain if we take the stock instance of deduction that is always given in books on logic, namely 'All men are mortal; Socrates is a man, therefore Socrates is mortal.' In this case what we really know beyond reasonable doubt is that certain men, A, B, C, were mortal, since, in fact, they have died. If Socrates is one of these men it is foolish to go the roundabout way through 'all men are mortal' to arrive at the conclusion that probably Socrates is mortal. If Socrates is not one of the men on whom our induction is based we shall still do better to argue straight from our A, B, C, to Socrates, than to go round by the general proposition, 'all men are mortal.' For the probability that Socrates is mortal is greater, on our data, than the probability that all men are mortal. (This is obvious, because if all men are mortal, so is Socrates; but if Socrates is mortal, it does not follow that all men are mortal.) Hence we shall reach the conclusion that Socrates is mortal, with a greater approach to certainty if we make our argument purely inductive than if we go by way of 'all men are mortal' and then use deduction."

Many years ago there appeared, principally owing to - $P . P$. pp. 123-125. 
the initiative of Dr. F. C. S. Schiller of Oxford, England, a comic number of Mind. The idea was extraordinarily good, not so the execution. A German friend of Dr. Schiller was puzzled by the appearance of the advertisements which had a doubtfully humorous appearance. However, by a syllogistic process, he acquired information which was new and useful to him, and thus incidentally refuted Mill. Presumably he started from the title of the magazine (Mind!), for a mark of exclamation seems nearly always in German to be a sign of an intended joke (including of course the mark after the politeness expressed in the first sentence of a private letter or a public address). There would be, then, the following syllogism:

This is a book of would-be jokes (i. e., everything in this book is a would-be joke);

This advertisement is in this book;

Therefore, this advertisement is a would-be joke.

Thus the syllogism may be almost as powerful an agent in the detection of humor as M. Bergson's criterion shortly to be described.

THE MORTALITY OF SOCRATES..

The mortality of Socrates is so often asserted in books on logic that it may be as well briefly to consider what it means. The phrase "Socrates is mortal" may be thus defined: "There is at least one instant $t$ such that $t$ has not to Socrates the one-many relation $\mathrm{R}$ which is the converse of the relation 'exist at,' and all instants following $t$ have not the relation $\mathrm{R}$ to Socrates, and there is at least one instant $t^{\prime}$ such that neither $t^{\prime}$ nor any instant preceding $t^{\prime}$ has the relation $\mathrm{R}$ to Socrates."

This definition has many merits. In the first place, no assumption is made that Socrates ever lived at all. In the second place, no assumption is made that the instants of time form a continuous series. In the third place, no as- 
sumption is made as to whether Socrates had a first or last moment of his existence. If time be indeed a continuous series, then we can easily deduce ${ }^{7}$ that there must have been either a first moment of his existence or a last one, but not both; just as there seems to be either a greatest weight that a man can lift or a least weight that he cannot lift, but not both. ${ }^{8}$

IMPLICATION.

A distinguished philosopher ( $\mathrm{M}$ ) once thought that the logical use of the word "implication,"-any false proposition being said to "imply" any proposition true or false,is absurd, on the grounds that it is ridiculous to suppose that the proposition " 2 and 2 make 5 " implies the proposition " $\mathrm{M}$ is the Pope." This is a most unfortunate instance, because it so happens that the false proposition that 2 and 2 make 5 can rigorously be proved to imply that $M$, or anybody else other than the Pope, is the Pope. For if 2 and 2 make 5 , since they also make 4 , we could conclude that 5 is equal to 4 . Consequently, subtracting 3 from both sides, we conclude that 2 would be equal to I. But if this were true, since $\mathrm{M}$ and the Pope are two, they would be one, and obviously then $M$ would be the Pope.

\section{DENIAL OF GENERALITY, AND GENERALITY OF DENIAL.}

The conclusion of a certain song ${ }^{\ominus}$ about a young man who poisoned his sweetheart with sheep's-head broth, and was frightened to death by a voice exclaiming:

\footnotetext{
"Where's that young maid

What you did poison with my head?"
}

at his bedside, gives rise to difficulties which are readily solved by a symbolism that brings into relief the principle that the denial of a universal and non-existential proposition

"From "Dedekind's axiom" (E. N., p. 11).

${ }^{8}$ Cf. M., April, 1908.

- To which De Morgan drew attention in a letter; see (Mrs.) S. E. De Morgan, Memoir of Augustus De Morgan, London, 1882, p. 324. 
is a particular and existential one. The conclusion of the song is :

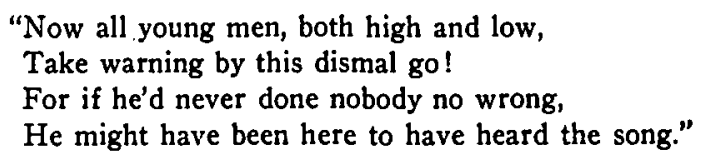

It is an obvious error, say Whitehead and Russell, ${ }^{10}$ though one easy to commit, to assume that the cases: (I) all the propositions of a certain class are true; and (2) no proposition of the class is true; are each other's contradictories. However, in the modification ${ }^{11}$ of Frege's symbolism which was used by Russell,
(I) is
(x). $x$,

and (2) is

$(x)$. not $x$;

while the contradictory of (I) is

$$
\text { not }(x) . x \text {. }
$$

The last line of the above verse may, then, be written

$$
(t) . \operatorname{not}(x) . \operatorname{not} \operatorname{not} \varphi(x, t) \text {, }
$$

where " $\varphi(x, t)$ " denotes the unasserted propositional function "the doing wrong to the person $x$ at the instant $t$. ." By means of the principle of double negation we can at once simplify the above expression into:

$$
(t) \cdot \operatorname{not}(x) \cdot \varphi(x, t) \text {; }
$$

which can be thus read: "If at every instant of his life there was at least one person $x$ to whom he did no wrong (at that instant)." It is difficult to imagine any one so sunk in iniquity that he would not satisfy this hypothesis. We are forced, then, unless our imagination for evil is to be distrusted, to conclude that any one might have been there to have heard that song. Now this conclusion is probably ${ }^{10}$ P. M., p. 16.

11 However, here, for the printer's convenience, we depart from Mr. Russell's usage so far as to write "not" for a curly minus-sign. 
false, possibly on physical grounds, and certainly on esthetic grounds.

According as the symbol for "not" comes before the $(x)$ or between the $(x)$ and the $\varphi x$, we have an expression of what Frege called respectively the denial of generality, and the generality of denial. The denial of the generality of a denial is the form of all existential propositions, while the assertion of or denial of generality is the general form of all non-existential or universal propositions.

LOGICAL ADDITION AND THE NATURE OF SYMBOLISM.

Frequently ordinary language contains subtle psychological implications which cannot be translated into symbolic logic except at great length. Thus if a man (say Mr. Jones) wishes to speak collectively of himself and his wife, the order of the mentioning of the terms in the class considered and the names applied to these terms are, logically speaking, irrelevant. And yet, more or less definite information is given about Mr. Jones, provided that he is an Englishman, according as he talks to his friends of

(I) Mrs. Jones and I,

(2) I (or me) and my wife (or missus),

(3) My wife and I,

or (4) I (or me) and Mrs. Jones.

In case ( $\mathrm{I}$ ) one is probably correct in placing Mr. Jones among the clergy or the small professional men who make up the bulk of the middle-class; in case (2) one would conclude that $\mathrm{Mr}$. Jones belonged to the lower middle-class; the form ( 3 ) would be used by Mr. Jones if he were a member of the upper, upper middle, or lower classes; while form (4) is only used by retired shop-keepers of the lower middle-class of which a male member usually combines belief in the supremacy of man with belief in the dignity of his wife as well as himself. A further complication is 
introduced if a wife is referred to as "the wife." This has already been briefly referred to in my note on "The."12 Cases (2) and (3) then each give rise to one more case. Cases (I) and (4) do not, since nobody has hitherto referred to his wife as "the Mrs. Jones,"-at least without a qualifying adjective before the "Mrs."

On the other hand, certain descriptive phrases and certain propositions can be expressed more shortly and more accurately by means of symbolic logic. Let us consider the proposition: "No man marries his deceased wife's sister." If we assume, as a first approximation, that all marriages are fertile, and that all children are legitimate, then, with only four primitive ideas: the relation of parent to child (P) and the three classes of males, females, and dead people, we can define "wife" (a female who has the relation formed by taking the relative product of $\mathrm{P}$ and $\mathrm{P}^{13}$ to a male), "sister," "deceased wife," and "deceased wife's sister" in terms of these ideas and of the fundamental notions of logic. Then the proposition: "no man marries his deceased wife's sister," can be expressed unambiguously by about twenty-nine simple signs on paper, whereas, in words, the unasserted statement consists of no less than thirty-four letters. Although, legally speaking, we should have to adopt somewhat different definitions and possibly increase the complications of our proposition, it must be remembered that, on the other hand, we always reduce the number of symbols in any proposition by increasing the number of definitions in the preliminaries to it.

By such means we may advance a step toward making legal definitions and propositions exact, and thus logic can make contributions to law in return for those made by law to $\operatorname{logic} .^{14}$

12 See M., Oct., 1911, Vol. XXI, p. 492.

${ }^{28}$ C. S. Peirce's notation for the relation "converse of P."

14 See $M$, Oct., 1911, Vol. XXI, pp. 484-485, 492. 


\section{IDENTITY OF CLASSES.}

I once heard of a somewhat meritorious lady who was extremely conventional, and, on the slender grounds of carefully acquired habits of preferring the word "woman" to the word "lady" and of going to the post-office without a hat, imagined that she was unconventional and altogether a remarkable person, and once remarked with great satisfaction that she was a very queer person, and that nothing shocked her "except, of course, bad form."

Thus, she asserted that all the things which shocked her were actions in bad form; and she would undoubtedly agree, though she did not actually state it, that all the things which were done in bad form would shock her. Consequently she asserted that the class of things which shocked her was the class of actions in bad form. Consequently the statement of this lady that some or all of the actions done in bad form shocked her is an identical proposition of the form: "nothing shocks me, except, of course, the things which do, in fact, shock me"; and this statement the lady certainly did not intend to make.

This excellent lady, had she but known it, was logically justified in making any statement whatever about her unconventionality. For the class of her unconventional actions was the null class. Thus she might logically have made inconsistent statements about this class of actions. As a matter of fact she did make inconsistent statements, but unfortunately she justified them by stating that, "It is the privilege of woman to be inconsistent." She was one of those persons who say things like that.

\section{ETHICAL APPLICATIONS OF THE LAW OF IDENTITY.}

It may be remembered that Mr. Podsnap remarked, with sadness tempered by satisfaction, that he regretted to say that "Foreign nations do as they do do." Besides aiding the comforting expression of moral disapproval, the 
law of identity has yet another useful purpose in practical ethics: It serves the welcome purpose of providing an excuse for infractions of the moral law. There was once a man who treated his wife badly, was unfaithful to her, was dishonest in business, and was not particular in his use of language; and yet his life on earth was described in the lines:

"This man maintained a wife's a wife,
Men are as they are made,
Business is business, life is life,
And called a spade a spade."

One of the objects of Mr. G. E. Moore's Principia Ethica ${ }^{15}$ was to argue that the word "good" means simply good, and not pleasant or anything else. Appropriately enough, this book bore on its title-page the quotation from the preface to the Sermons, published in 1726, of Bishop Joseph Butler, the author of the Analogy: "Everything is what it is and not another thing."

But another famous Butler-Samuel Butler, the author of Hudibras,-went farther than this and maintained that identities were the highest attainment of metaphysics itself. At the beginning of the first Canto of Hudibras, in the description of Hudibras himself, Butler wrote:

"He knew what's what, and that's as high As metaphysic wit can fly."

I once conducted what I imagined to be an esthetic investigation for the purpose of discovery, by the continual use of the word "Why?"10 the grounds upon which certain people choose to put milk into a tea-cup before the tea. I was surprised to discover that it was an ethical, and not an esthetic problem; for I soon elicited the fact that it was done because it was "right." A continuance of my patient questioning elicited further evidence of the fundamental character of the principle of identity in ethics; for it was right, I learned, because "right is right."

15 Cambridge, 1903.

${ }^{10}$ Cf. P. E., p. 2. 
It appears that some people unconsciously think that the principle of identity is the foundation, in certain religions, of the reasons which can be alleged for moral conduct, and are surprised when this fact is pointed out to them. The late Sir Leslie Stephen, when traveling by railway, fell into conversation with an officer of the Salvation Army, who tried hard to convert him. Failing in this laudable endeavor, the Salvationist at last remarked: "But if you aren't saved, you can't go to heaven!" "That, my friend," replied Stephen, "is an identical proposition."

\section{DIGNITY.}

We have seen ${ }^{17}$ that logical implication is often an enemy of dignity. The subject of dignity is not usually considered in treatises on logic, but, as we have remarked, ${ }^{18}$ many mathematicians implicitly or explicitly seem to fear either that the dignity of mathematics will be impaired if she follow out conclusions logically, or that only an act of faith can save us from the belief that, if we followed out conclusions logically, we should find out something alarming about the past, present, or future of mathematics.

Thus it seems necessary to inquire rather more closely into the nature of dignity, with a view to the discovery of whether it is, as is commonly supposed, a merit in life and logic.

The chief use of dignity is to veil ignorance. Thus it is well known that the most dignified people, as a rule, are schoolmasters; and schoolmasters are usually so occupied with teaching that they have no time to learn anything. And because dignity is used to hide ignorance, it is plain that impudence is not always the opposite of dignity, but that dignity is sometimes impudence. Dignity is said to inspire respect; and this may be in part why respect for

${ }^{17} M$, Oct., 1911, Vol. XXI, p. 497.

18 Ibid. Cf. also the section below on "The Paradoxes of Logic." 
others is an error of judgment and self-respect is ridiculous.

Self-respect is, of course, self-esteem. William James has remarked that self-esteem depends, not simply upon our success, but upon the ratio of our success to our pretensions, and can therefore be increased by diminishing our pretensions. Thus if a man is successful, but only then, can he be both ambitious and dignified. James also implies that happiness increases with self-esteem. Likeness of thought with one's friends, then, does not make one happy, for otherwise a man who esteemed himself little would be indeed happy. Also if a man is unhappy he could not, from our premises, by the principles of the syllogism and of contraposition, be dignified,- -a conclusion which should be fatal to many novelists' heroes.

A reflection on pessimism to which this discussion gives rise is the following. It would appear that a man's selfesteem would be increased by a conviction of the unworthiness of his neighbors. A man, therefore, who thinks that the world and all its inhabitants, except himself, are very bad, should be extremely happy. In fact the effects would hardly be distinguishable from those of optimism. And optimism, as everybody knows, is a state of mind induced by stupidity.

\section{THE PARADOXES OF LOGIC.}

We have already ${ }^{19}$ referred to the contempt shown by some mathematicians for exact thought, which they condemn under the name of "scholasticism." An example of this is given by Schoenflies in the second part of his publication usually known as the Bericht über Mengenlehre. ${ }^{20}$ $\mathrm{Here}^{21}$ a battle-cry in italics:

18 M, Oct., 1911, Vol. XXI, p. 486.

20 Die Entwickelung der Lehre von den Punktmannigfaltigkeiten Bericht, erstattet der deutschen Mathematiker-Vereinigung, Leipsic, 1908.

${ }^{21}$ Ibid., p. 7. The battle-cry is: "Gegen jede Resignation, aber auch gegen jede Scholastik i" 
"Against all resignation, but also against all scholasticism!"

found utterance. Later on Schoenflies ${ }^{22}$ got bolder and adopted a more personal battle-cry, also in italics and with a whole line to itself:

"For Cantorism but against Russellism!"

"Cantorism" means the theory of transfinite aggregates and numbers erected for the most part by Georg Cantor. Shortly speaking, the great sin of "Russellism" is to have gone too far in the chain of logical deduction for many mathematicians, who were perhaps, like Schoenflies, ${ }^{23}$ blinded by their rather uncritical love of mathematics. Thus it comes about that Schoenflies ${ }^{24}$ denounces Russellism as "scholastic and unhealthy." This queer blend of qualities would surely arouse the curiosity of the most blasé as to what strange thing Russellism must be. ${ }^{25}$

Schoenflies ${ }^{26}$ said that some mathematicians attributed to the logical paradoxes which have given Russell so much trouble to clear up, "especially to those that are artificially constructed, a signification that they do not have." Yet no grounds were given for this assertion, from which it might be concluded that the rigid examination of any concept was unimportant. The paradoxes are simply the necessary results of certain logical views which are currently held, which views do not, except when they are examined rather closely, appear to contain any difficulty. The contradiction is not felt, as it happens, by people who confine

22 "Ueber die Stellung der Definition in der Axiomatik," Jahresber. der deutsch. Math.-Ver., Vol. XX, 1911, pp. 222-255. The battle-cry is on p. 256 and is: "Für den Contorismus aber gegen den Russellismus!"

${ }^{23}$ Ibid., p. 251. "Es ist also", he exclaims with the eloquence of emotion and the emotion of eloquence, "nicht die Geringschätzung der Philosophie, die mich dabei treibt, sondern die Liebe zur Mathematik;..."

24 Ibid.

${ }^{25}$ Cf. for this, $M$, Jan., 1912, Vol. XXII, pp. 149-158.

20 Bericht, 1908 , p. $76 n$; cf. p. 72. 
their attention to the first few number-classes of Cantor, and this seems to have given rise to the opinion, which it is a little surprising to find that some still hold, that cases not usually met with, though falling under the same concept as those usually met with, are of little importance. One might just as well maintain that continuous but not differentiable functions are unimportant because they are artificially constructed,-a term which I suppose means that they do not present themselves when unasked for. Rather should we say that it is by the discovery and investigation of such cases that the concept in question can alone be judged, and the validity of certain theorems-if they are valid-conclusively proved. That this has been done, chiefly by the work of Russell, is simply a fact; that this work has been and is misunderstood by many ${ }^{27}$ is regrettable for this reason, among others, that it proves that, at the present time, as in the days in which Gulliver's Travels were written, some mathematicians are bad reasoners.

Nearly all mathematicians agreed that the way to solve these paradoxes was simply not to mention them; but there was some divergence of opinion as to how they were to be unmentioned. It was clearly unsatisfactory merely not to mention them. Thus Poincaré was apparently of opinion that the best way of avoiding such awkward subjects was to mention that they were not to be mentioned. $\mathrm{But}^{28}$ "one might as well, in talking to a man with a long nose, say: 'When I speak of noses, I except such as are inordinately long,' which would not be a very successful effort to avoid a painful topic."

Schoenflies, in his paper of I9I I mentioned above, adopted the convenient plan of referring these logical difficulties at the root of mathematics to a department of 27 E. g., in F. Hausdorf's review of Russell's Principles of 1903 in the Vierteljahrsschr. für wiss. Philos. und Soziologie.

${ }^{28}$ Russell, A. J. M., Vol. XXX, 1908, p. 226. 
knowledge which he called "philosophy." He said ${ }^{29}$ of the theory of aggregates that though "born of the acuteness of the mathematical spirit, it has gradually fallen into philosophical ways, and has to some extent the compelling force which dwells in the mathematical process of conclusion."

The majority of mathematicians have followed Schoenflies rather than Poincaré, and have thus adopted tactics rather like those of the March Hare and the Gryphon, ${ }^{80}$ who promptly changed the subject when Alice raised awkward questions. Indeed, the process of the first of these creatures of a child's dream is rather preferable to that of Schoenflies. The March Hare refused to discuss the subject because he was bored when difficulties arose. Schoenflies would not say that he was bored,-he professed interest in philosophical matter,-but simply called the logical continuation of a subject by another name when he did not wish to discuss this continuation, and thus implied that he had discussed the whole subject. Further, Schoenflies would not apparently admit that the one method of logic could be applied to the solution of both mathematical and philosophical problems, in so far as these problems are soluble at all; but the March Hare, shortly before the remark we have just quoted, rightly showed great astonishment that butter did not help to cure both hunger and watches that would not go. ${ }^{31}$ The judgment of Schoenflies by which certain apparently mathematical questions were condemned as "philosophical" rested on grounds as flimsy as those in the Dreyfus Case or the Trial in Wonderland. ${ }^{32}$

\section{MODERN LOGIC AND SOME PHILOSOPHICAL ARGUMENTS.}

The most noteworthy reformation of recent years in logic is the discovery and development by Mr. Bertrand

29 Loc. cit., p. 222.

${ }^{81}$ See Appendix D.
30 See Appendix C.

${ }^{82}$ See Appendix E. 
Russell of the fact that the paradoxes, - of Burali-Forti, Russell, König, Richard and others, - which have appeared of late years in the mathematical theory of aggregates and have just been referred to, are of an entirely logical nature, and that their avoidance requires us to take account of a principle which has been hitherto unrecognized, and which renders several well-known arguments in refutation of scepticism, agnosticism, and the statement of a man that he asserts nothing, invalid.

Dr. Whitehead and Mr. Russell say in their P. M.: ${ }^{83}$ "The principle which enables us to avoid illegitimate totalities may be stated as follows: "Whatever involves all of a collection must not be one of the collection,' or conversely: 'If, provided a certain collection had a total, it would have members only definable in terms of that total, then the said collection has no total.' We shall call this the 'vicious-circle principle,' because it enables us to avoid the vicious circles involved in the assumption of illegitimate totalities. Arguments which are condemned by the vicious-circle principle will be called 'vicious-circle fallacies.' Such arguments, in certain circumstances, may lead to contradictions, but it often happens that the conclusions to which they lead are in fact true, though the arguments are fallacious. Take, for example, the law of excluded middle in the form 'all propositions are true or false.' If from this law we argue that, because the law of excluded middle is a proposition, therefore the law of excluded middle is true or false, we incur a vicious-circle fallacy. 'All propositions' must be in some way limited before it becomes a legitimate totality, and any limitation which makes it legitimate must make any statement about the totality fall outside the totality. Similarly the imaginary sceptic who asserts that he knows nothing and is refuted by being asked if he knows that he knows nothing, has asserted nonsense, and has been falla-

s P. 40. 
ciously refuted by an argument which involves a viciouscircle fallacy. In order that the sceptic's assertion may become significant it is necessary to place some limitation upon the things of which he is asserting his ignorance; the proposition that he is ignorant of every member of this collection must not itself be one of the collection. Hence any significant scepticism is not open to the above form of refutation."

THE HIERARCHY OF JOKES.

Jokes may be divided into various types. Thus a joke or class of jokes which is itself the subject of a joke can only be the subject of a joke of higher order. Otherwise we would get the same vicious-circle fallacy which gives rise to so many paradoxes in logic and mathematics. Thus a certain Oxford scholar succeeded, to his own satisfaction, in reducing all jokes to primitive types consisting of thirtyseven proto-Aryan jokes. When any proposition was propounded to him he would reflect and afterwards pronounce on the question as to whether the proposition was a joke or not. If he decided, by his theory, that it was a joke he would solemnly say: "There is that joke." If this narration is accepted as a joke, since it cannot be reduced to one of the proto-Aryan jokes under pain of leading us to commit a vicious-circle fallacy, we must conclude that there is at least one joke which is not proto-Aryan; and, in fact, is of a higher type. There is no great difficulty, in point of principle, in forming a hierarchy of jokes of various types. Thus a joke of the fourth type (or order) is as follows: A joke of the first order was told to a Scotchman, who, as we would expect, was unable to see it. The person $(A)$ who told this joke told the story of how the joke was received to another Scotchman, thereby making a joke about a joke of the first order, and thus making a joke of the second order. $A$ remarked on this joke that no joke 
could penetrate the head of the Scotchman to whom the joke of the first order was told even if it were fired into his head with a gun. The Scotchman, after severe thought, replied: "But ye couldn't do that, ye know!" $A$ repeated the whole story, which constituted a joke of the third order, to a third Scotchman. This Scotchman again, after prolonged thought, replied: "He had ye there!" This whole story is a joke of the fourth order.

Most known jokes are of the first order, for the simple reason that the majority of people find that the slightest mental effort effectually destroys any perception of humor. It seems to me that a joke becomes more pleasurable in proportion as logical faculties are brought into play by it, and hence that logical power is allied, or possibly identical, with the power of grasping more subtle jokes. The jokes which amuse the frequenters of music-halls, Conservatives, and $\mathrm{Mr}$. Bergson-and which usually deal with accidents, physical defects, mothers-in-law, foreigners, or over-ripe cheese-are usually jokes of the first order. Jokes of the second, and even of the third, order appeal to ordinary well-educated people; jokes of higher order require either special ability or a sound logical training on the part of the hearer if the joke is to be appreciated; while jokes of transfinite order presumably only excite the inaudible laughter of the gods.

\section{LAUGHTER.}

In a review ${ }^{84}$ of Bergson's book on Laughter, ${ }^{35} \mathrm{Mr}$. B. Russell has remarked:

"It has long been recognized by publishers that everybody desires to be a perfect lady or gentleman (as the case may be); to this fact we owe the constant stream of

\footnotetext{
s4 "The Professor's Guide to Laughter," The Cambridge Review, Vol. XXXII, 1912, pp. 193-194.

ss Laughter, an Essay on the Meaning of the Comic, English translation by C. Brereton and F. Rothwell, London, 1911.
} 
etiquette-books. But if there is one thing which people desire even more, it is to have a faultless sense of humor. Yet so far as I know there is no book called 'Jokes without Tears, by Mr. McQuedy.' This extraordinary lacuna has now been filled. Those to whom laughter has hitherto been an unintelligible vagary, in which one must join, though one could never tell when it would break out, need only study Mr. Bergson's book to acquire the finest flower of Parisian wit. By observing a very simple formula they will know infallibly what is funny and what is not; if they sometimes surprise their unlearned friends they have only to mention their authority in order to silence doubt. 'The attitudes, gestures and movements of the human body,' says $M$. Bergson, 'are laughable in exact proportion as that body reminds us of a mere machine.' When an elderly gentleman slips on a piece of orange peel and falls, we laugh, because his body follows the laws of dynamics instead of a human purpose. When a man falls from a scoffolding and breaks his neck on the pavement, we presumably laugh even more, since the movement is even more completely mechanical. When the clown makes a bad joke for the first time, we keep our countenance, but at the fifth repetition we smile, and at the tenth we roar with laughter, because we begin to feel him a mere automaton. We laugh at Molière's misers, misanthropists and hypocrites, because they are mere types mechanically dominated by a master impulse. Presumably we laugh at Balzac's characters for the same reason; and presumably we never smile at Falstaff, because he is individual throughout."

The review concludes with the reflection that "it would seem to be impossible to find any such formula as M. Bergson seeks. Every formula treats what is living as if it were mechanical, and is therefore by his own rule a fitting object of laughter." Now this undoubtedly true conclu- 
sion has been obtained, as is readily seen, by a vicious-circle fallacy.

\section{HISTORICAL CRITICISM.}

From a problem in Diophantus's Arithmetic about the price of some wine it would seem that the wine was of poor quality, and Paul Tannery has suggested that the prices mentioned for such a wine are higher than were usual until after the end of the second century. He therefore rejected the view which was formerly held that Diophantus lived in that century. ${ }^{38}$

The same method applied to a problem given by the ancient Hindu algebraist Brahmagupta, who lived in the seventh century after Christ, might result in placing Brahmagupta in prehistoric times. This is the problem : $:^{87}$ "Two apes lived at the top of a cliff of height $h$, whose base was distant $m h$ from a neighboring village. One descended the cliff and walked to the village, the other flew up a height $x$ and then flew in a straight line to the village. The distance traversed by each was the same. Find $x$."

THE HUMOR OF MATHEMATICIANS.

Brahmagupta's problem appears to be the earliest instance of a kind of joke which has been much used by mathematicians. For the sake of giving a certain picturesqueness to the data of problems and so to excite that sort of interest which is partly expressed by a smile, mathematicians have got into the habit of talking, for example, of monkeys in the form of geometrical points climbing up massless ropes. Prof. P. Stäckel ${ }^{38}$ truly remarked that physiological mechanics-the mechanics of bones, muscles, and so on-is wholly different from this. There was once a

${ }^{36} \mathrm{~W}$. W. Rouse Ball, A Short Account of the History of Mathematics, 4th ed., London, 1908, p. 109.

${ }^{37}$ Ibid., pp. 148-149.

${ }^{38}$ Encykl. der math. Wiss., Vol. IV, part I, p. 474. 
lecturer on mathematics at Cambridge, England, who used yearly to propound to his pupils a problem in rigid dynamics which related to the motion of a garden roller supposed to be without mass or friction, when a heavy and perfectly rough insect walked round the interior of it in the direction of normal rolling.

Hitherto this has been the only mathematical outlet for the humor of mathematicians; and those who really had the interests of mathematics at heart saw with alarm the growing tendency towards scholasticism in mathematical jokes. Fortunately the discovery of logic by some mathematicians has removed this danger. Still to many mathematicians logic is still unknown, and to them-to Prof. A. Schoenflies for example-modern mathematics, owing to its alliance with logic, appears to be sinking into scholasticism. It is true that the word "scholasticism" is not used by Professor Schoenflies in any intentionally precise signification, but merely as a vague epithet of disapproval, very much as the word "socialism" is used by the ordinary philistine, and this would certainly serve as a sufficient excuse. But no excuse is needed: these opinions are themselves a source of mathematical jokes.

THE CONVERSION OF RELATIONS.

The "Conversion of Relations" does not mean what it might be supposed to mean; it has nothing to do with what Kant called "the wholesome art of persuasion." What concerns us here is the convertibility of a logical relation. If $A$ has a certain relation $R$ to $B$, the relation of $B$ to $A$, which may be denoted by $\check{R}$, is called the converse of $R$. As De Morgan ${ }^{80}$ remarked, this conversion may sometimes present difficulties. The following is De Morgan's example:

"Teacher: 'Now, boys, Shem, Ham and Japheth were

s9 Trans. Camb. Phil. Soc., Vol. X, 1864, part II, note on page 334. 
Noah's sons; who was the father of Shem, Ham and Japheth?' No answer.

"Teacher: 'Boys, you know Mr. Smith, the carpenter, opposite; has he any sons?'

"Boys: 'Oh! yes Sir! there's Bill and Ben.'

"Teacher: 'And who is the father of Bill and Ben Smith?'

"Boys: 'Why Mr. Smith to be sure.'

"Teacher: 'Well, then, once more, Shem, Ham and Japheth were Noah's sons; who was the father of Shem, Ham and Japheth?'

"A long pause; at last a boy, indignant at what he thought the attempted trick, cried out: 'It couldn't have been Mr. Smith.' These boys had never converted the relation of father and son,..."

\section{FINITE AND INFINITE.}

I was once shown a statement made by an eminent mathematician of Cambridge (England) from which one would conclude that this mathematician thought that finite distances became infinite when they were great enough. In one of those splendidly printed books, bound in blue, published by the University Press, and sold at about a guinea as a guide to some advanced branch of pure mathematics, one may read, even in the second edition published in 1900, the words: "Representation [of a complex variable] on a plane is obviously more effective for points at a finite distance from the origin than for points at a very great distance."

Plainly some of the points at a very great distance are at a finite distance, for the same author mentions that Neumann's sphere for representing the positions of points on a plane "has the advantage.... of exhibiting the uniqueness of $z=\infty$ as a value of the variable." 
THE MATHEMATICAL ATTAINMENTS OF TRISTRAM SHANDY.

Tristram Shandy ${ }^{40}$ said that his father was sometimes a gainer by a misfortune; for if the pleasure of haranging about it was as ten, and the misfortune itself only as five, he gained "half in half," and was well off again as if the misfortune had never happened.

Suppose that the unit (arbitrary) of pleasure is denoted by A, Tristram Shandy, by neglecting, in this ethical discussion, to introduce negative quantities (Kant's pamphlet advocating this introduction into philosophy was made subsequently) $)^{4 i}$ apparently made $\mathrm{I} 5 \mathrm{~A}$ to result, and this can hardly be maintained to be the half of Io $\mathrm{A}$. It is possible however that Tristram Shandy succeeded in proving the apparently paradoxical equation

$$
\text { I } 5 \mathrm{~A}=5 \mathrm{~A}
$$

by remarking that the axiom "the whole is greater than the part" does not always hold. This remark follows at once from what Mr. Russel1" has called "The Paradox of Tristram Shandy." This paradox is described by Mr. Russell as follows:

"Tristram Shandy, as we know, took two years writing the history of the first two days of his life, and lamented that, at this rate, material would accumulate faster than he could deal with it, so that he could never come to an end. Now I maintain that, if he had lived for ever, and not wearied of his task, then, even if his life had continued as eventfully as it began, no part of his biography would have remained unwritten."

This paradox is strictly correlative to the well-known

${ }^{\circ 0}$ Cf. a letter of De Morgan's in Mrs. De Morgan's Memoir of Augustus De Morgan, p. 324.

${ }^{41}$ Kant's tract was published in 1763 , while Tristram Shandy was published in 1760 .

2 Pr. M., pp. 358-359; cf. M, Jan., 1912, Vol. XXII, p. 187. 
paradox of Zeno's about Achilles and the Tortoise. "The Achilles proves that two variables in a continuous series, which approach equality from the same side, cannot ever have a.common limit: the Tristram Shandy proves that two variables which start from a common term, and proceed in the same direction, but diverge more and more, may yet determine the same limiting class (which however is not necessarily a segment, because segments were defined as having terms beyond them). The Achilles assumes that whole and part cannot be similar, and deduces a paradox; the other, starting from a platitude, deduces that whole and part may be similar. For common sense, it must be confessed, that is a most unfortunate state of things." And Mr. Russell considers that, in the face of proofs, it ought to commit suicide in despair.

Now I suggest the extremely unlikely possibility that Tristram Shandy, by reflection on his own life and literary labors, was led to the correct course of accepting the paradox which resulted from this reflection and rejecting the Achilles. Thus, he concluded that an infinite whole may be similar (or, in Cantor's terminology, equivalent) to a proper part of itself, and hence, by a confusion of similarity with identity (or equivalence with equality) which he shares with some subsequent philosophers," that a whole may be equal to a proper part of itself. If $A$ is an infinite class it is not difficult to see that we can have

$$
\text { Io } \mathrm{A}=5 \mathrm{~A} \text {. }
$$

In this way many have avoided an opinion which rests on no better foundation than that formerly entertained by the inductive philosophers of Central Africa, that all men are black. ${ }^{40}$

${ }^{48}$ Cf. Pr. M., pp 350, 358-359; M., Vol. XXII, 1912, p. 157.

14 Cf., for example, Cosmo Guastella, Dell' infinito, Palermo, 1912.

45 Cf. Russell, Pr. M., p. 360. 
THE HARDSHIPS OF A MAN WITH AN UNLIMITED INCOME.

I once heard a man refer to his income as limited, in order to illustrate the hardships of a class of men, of which he of course was one, in having to pay a somewhat high income-tax. It is obvious that this man spoke enviously, and consequently admitted the existence of more fortunately placed individuals such that at least one had an unlimited income. A little reflection would have shown the man that he was not taking up a paradoxical attitude. A "paradoxical attitude" is of course the assertion of one or more propositions of which the truth cannot be perceived by a philosopher-and particularly an idealist-and can be perceived by a logician and occasionally but not always by a man of common sense. Such propositions are: "The cat is hungry," "Columbus discovered America," and "A thing which is always at rest may move from the position A to the different position B."

Now if a man had an unlimited income it is an immediate inference that, however low income-tax might be, he would have to pay annually to the exchequer of his nation a sum equal in value to his whole income. Further, if his income was derived from a capital invested at a finite rate of interest (as is usual), the annual payments of incometax would each be equal in value to the man's whole capital If, then, the man with an unlimited income chose to be discontented, he would be sure of a sympathetic audience among philosophers and business acquaintances; but discontent could not last long, for the thought of the difficulties he was putting in the way of the chancellor of the exchequer, who would find the drawing up of his budget most puzzling, would be amusing. Again, the discovery that, after paying an infinite income-tax, the income would be quite undiminished, would obviously afford an uneasy satisfaction. 
THE RELATIONS OF MAGNITUDE OF CARDINAL NUMBERS.

The theorems of cardinal arithmetic are frequently used in ordinary conversation. What is known as the Schröder-Bernstein theorem was used, long before Bernstein or Schröder, by Thurlow, afterward the law-lord Lord Thurlow, when an undergraduate of Trinity College, Dublin. Thurlow was rebuked for idleness by the provost (I think) who said to him: "Whenever I look out of the window, Mr. Thurlow, I see you crossing the court." The provost thus asserted a one-one correspondence between the class $A$ of his acts of looking out of the window and a part of the class B of Thurlow's acts of crossing the court. Thurlow asserted in reply a one-one correspondence between B and a part of A: "Whenever I cross the court I see you looking out of the window." The SchröderBernstein theorem then allows us to conclude that there is a one-one correspondence between the classes $\mathrm{A}$ and $\mathrm{B}$. That $A$ and $B$ were finite classes is not the fault of the provost or Thurlow; nor is it relevant logically.

THE EVIDENCE OF GEOMETRICAL PROPOSITIONS.

It has often been maintained that the twentieth proposition of the first book of Euclid-that two sides of a triangle are together greater than the third side-is evident even to asses. This does not however seem to me generally true. I once asked a coastguardsman the distance from A to B; he replied: "eight miles." On further inquiry $I$ elicited the fact that the distance from $A$ to $C$ was two miles and the distance from $C$ to $B$ was twentytwo miles. Now the paths from $A$ to $B$ and from $C$ to $B$ were by sea, while the path from $A$ to $C$ was by land. Hence if the path by land was rugged and the distance along the road was two miles, it would appear that the coastguardsman believed that not only could one side of a triangle be 
greater than the other two but that one straight side of a triangle might be greater than one straight side and any curvilinear side of the same triangle. The only escape from part of this astonishing creed would be by assuming that the distance of two miles from $\mathrm{A}$ to $\mathrm{C}$ was measured "as the crow flies," while the road A to $C$ was so hilly that a pedestrian would traverse more than fourteen miles when proceeding from $A$ to $C$. Then indeed the coastguardsman could maintain the true proposition that there is at least one triangle $A B C$, with the side $A C$ curvilinear, such that the sum of the lengths of $A B$ and $A C$ is greater than the length of $\mathrm{BC}$, and only deny the twentieth proposition of the first book of Euclid.

Reasoning with the coastguardsman only had the effect of his adducing the authority of one Captain Jones in support of the accuracy of his data. Possibly Captain Jones held strange views as to the influence of temperature or other physical circumstances or even the nature of space itself on the lengths of lines in the neighborhood of the triangle $\mathrm{ABC}$.

ABSOLUTE AND RELATIVE POSITION,

Some people maintain that position in space or time must be relative because, if we try to determine the position of a body $\mathrm{A}$, if bodies $\mathrm{B}, \mathrm{C}, \mathrm{D}$ with respect to which the position of $A$ could be determined were not present, we should be trying to determine something about $\mathrm{A}$ without having our senses affected by other things. These people seem to me to be like the cautious guest who refused to say anything about his host's port-wine until he had tasted red ink.

"Wherein, then," says Mr. B. Russell," "lies the plausibility of the notion that all points are exactly alike? This notion is, I believe, a psychological illusion, due to the fact

46 Mind, N. S., No. 39 (July, 1901), pp. 313-314. 
that we cannot remember a point so as to know it when we meet it again. Among simultaneously presented points it is easy to distinguish; but though we are perpetually moving, and thus being brought among new points, we are quite unable to detect this fact by our senses, and we recognize places only by the objects they contain. But this seems to be a mere blindness on our part,- there is no difficulty, so far as I can see, in supposing an immediate difference between points, as between colors, but a difference which our senses are not constructed to be aware of. Let us take an analogy: Suppose a man with a very bad memory for faces; he would be able to know, at any moment, whether he saw one face or many, but he would not be aware whether he had seen any of the faces before. Thus he might be led to define people by the rooms in which he saw them, and to suppose it self-contradictory that new people should come to his lectures, or that old people should cease to do so. In the latter point at least it will be admitted by lecturers that he would be mistaken. And as with faces, so with points,-inability to recognize them must be attributed, not to the absence of individuality, but merely to our incapacity."

Another form of this tendency is shown by Kronecker, Borel, Poincaré and many other mathematicians, who refuse mere logical determination of a conception and require that it be actually described in a finite number of terms. These eminent mathematicians were anticipated by the empirical philosopher who would not pronounce that the "law of thought" that A is either in the place B or not is true until he had looked to make sure. This philosopher was of the same school as J. S. Mill and Buckle, who seemed to have maintained implicitly not only that, in view of the fact that the breadth of a geometrical line depends upon the material out of which it is constructed, or upon which it is drawn, that there ought to be a paste- 
board geometry, a wooden geometry, a stone geometry, and so on $;^{47}$ but also that the foundations of logic are inductive in their nature. ${ }^{48}$ "We cannot," says Mill," conceive a round square, nor merely because no such object has ever presented itself in our experience, for that would not be enough. Neither, for anything we know, are the two ideas in themselves incompatible. To conceive a body all black and yet white, would only be to conceive two different sensations as produced in us simultaneously by the same object-a conception familiar to our experienceand we should probably be as well able to conceive a round square as a hard square, or a heavy square, if it were not that in our uniform experience, at the instant when a thing begins to be round, it ceases to be square, so that the beginning of the one impression is inseparably associated with the departure or cessation of the other. Thus our inability to form a conception always arises from our being compelled to form another contradictory to it."

THE LAW OF CONTRADICTION.

Considering the important place assigned by philosophers and logicians to the law of contradiction, the remark will naturally be resented by many of the older schools of philosophy and especially by Kantians, that "in spite of its fame we have found few occasions for its use."

\section{THE PRINCIPLE OF PERMANENCE.}

In their readiness to consider many different things as one thing,- to consider, for example the ratio 2 : I as the same thing as the cardinal number 2,- such mathematicians as Peacock, Hankel and Schubert were forestalled

47 J. B. Stallo, The Concepts and Theories of Modern Physics, 4th ed., London, 1900, pp. 217-227.

48 Ibid., pp. 140-144.

49 Examination of the Philosophy of Sir William Hamilton, Vol. I, p. 88, Amer. ed.

${ }^{\circ 0}$ P. $M$. , p. 116. 
by the Pigeon, who thought that Alice and the Serpent were the same creature, because both had long necks and ate eggs."

It is however doubtful whether the Pigeon would have followed the example of the mathematicians just mentioned so far as to embrace the creed of nominalism and so to feel no difficulty in subtracting from zero,-a difficulty which was pointed out with great acuteness by the Hatter ${ }^{52}$ and modern mathematical logicians.

NOMINALISM.

One of the chief differences between logicians and men of letters is that the latter mean many different things by one word, whereas the former do not-at least nowadays. Most mathematicians belong to the class of men of letters.

I once had a manservant who told me on a certain occasion that he "never thought a word about it." I was doubtful whether to class him with such eminent mathematicians as Helmholtz, Kronecker, Stolz, Pringsheim and Schubert, or as a supporter of Max Müller's theory of the identity of thought and language. However since the man was very untruthful, and I have heard that he meant what he said and said what he meant, ${ }^{\text {s8 }}$ the conclusion is probably correct that he really believed that the meanings of his words were not the words themselves. Thus I think it most probable that my manservant had been a mathematician but had escaped by the aid of logic.

IS THE MIND IN THE HEAD?

The contrary opinion has been maintained by idealists and a certain election agent with whom I once had to deal,

01 See Appendix F.

62 See Appendix G.

63 The Hatter (see Appendix $\mathrm{H}$ ) pointed out that there is a difference between these two assertions. Thus he clearly showed that he was a nominalist, and philosophically opposed to the March Hare, who had recommended Alice to say what she meant. 
and who remarked that something slipped his mind and then went out of his head altogether. At some period, then, a remembrance was in his head and out of his mind; his mind was not, then, wholly within his head. Also, one is sometimes assured that with certain people "out of sight is out of mind." What is in their minds is therefore in sight, and cannot therefore be inside their heads.

\section{APPENDIX A.}

T. L. G., p. 105 .

"She's in that state of mind," said the White Queen, "that she wants to deny something-only she doesn't know what to deny."

"A nasty, vicious temper," the White Queen remarked; and then there was an uncomfortable silence for a minute or two.

APPENDIX B.

H. S., p. 3.

"Just the place for a Snark! I have said it twice:

That alone should encourage the crew.

Just the place for a Snark! I have said it thrice:

What I tell you three times is true."

H. S., p. 50.

"'Tis the note of the Jubjub! Keep count, I entreat;

You will find I have told it you twice.

'Tis the song of the Jubjub! The proof is complete, If only I've stated it thrice."

\section{APPENDIX C.}

A. A. $W$., pp. I04-105.

The Hatter had told of his quarrel with Time, and Time's refusal now to do anything he asked: "....It's always six o'clock now!" 
A bright idea came into Alice's head. "Is that the reason so many tea things are put out here?" she asked.

"Yes, that's it," said the Hatter with a sigh: "it's always tea time, and we've no time to wash the things between whiles."

"Then you keep moving round, I suppose?" said Alice.

"Exactly so," said the Hatter: "As the things get used up."

"But what happens when you come to the beginning again?" Alice ventured to ask.

"Suppose we change the subject," the March Hare interrupted yawning. "I'm getting tired of this."

A. A. W., pp 145-146.

"And how many hours a day did you do lessons?" said Alice in a hurry to change the subject.

"Ten hours the first day," said the Mock Turtle, "nine the next and so on."

"What a curious plan!" exclaimed Alice.

"That's the reason they're called lessons," the Gryphon remarked: "because they lessen from day to day."

This was quite a new idea to Alice, and she thought it over a little before she made the next remark. "Then the eleventh day must have been a holiday?"

"Of course it was," said the Mock Turtle.

"And how did you manage on the twelfth?" Alice went on eagerly.

"That's enough about lessons," the Gryphon interrupted in a very decided tone....

\section{APPENDIX D.}

A. A. W., p. 99 .

"Two days wrong!" sighed the Hatter. "I told you butter wouldn't suit the works!" he added, looking angrily at the March Hare. 

plied.

"It was the best butter," the March Hare meekly re-

"Yes, but some crumbs must have got in as well," the Hatter grumbled; "you shouldn't have put it in with the breadknife."

The March Hare took the watch and looked at it gloomily: then he dipped it into his cup of tea, and looked at it again: but he could think of nothing better to say than his first remark, "It was the best butter, you know."

APPENDIX E.

A. A. W., pp. 180-187.

...."Consider your verdict," he [the King] said to the jury, in a low trembling voice.

"There's more evidence to come yet, please your Majesty," said the White Rabbit, jumping up in a great hurry: "this paper has just been picked up."

"What's in it ?" said the Queen.

"I haven't opened it yet," said the White Rabbit; "but it seems to be a letter written by a prisoner to somebody."

"It must have been that," said the King, "unless it was written to nobody, which isn't usual, you know."

"Who is it directed to?" said one of the jurymen.

"It isn't directed at all," said the White Rabbit, "in fact there's nothing written on the outside." He unfolded the paper as he spoke and added "it isn't a letter, after all: it's a set of verses."

"Are they in the prisoner's handwriting?" asked another of the jurymen.

"No, they're not," said the White Rabbit, "and that's the queerest thing about it." (The jury all looked puzzled.)

"He must have imitated somebody else's hand," said the King. (The jury brightened up again.)

"Please your Majesty," said the Knave, "I didn't write 
it, and they can't prove that I did: there's no name signed at the end."

"If you didn't sign it, said the King, that only makes the matter worse. You must have meant some mischief, or else you'd have signed your name like an honest man."

There was a general clapping of hands at this: it was the first really clever thing the King had said that day.

"That proves his guilt, of course," said the Queen: "so, off with...."

"It doesn't prove anything of the sort!" said Alice. "Why, you don't even know what they're about!"

"Read them," said the King.

The White Rabbit put on his spectacles. "Where shall I begin, please your Majesty?" he asked.

"Begin at the beginning," the King said very gravely, "and go on till you come to the end: then stop."

There was dead silence in the court, whilst the White Rabbit read out these verses:

"They told me you had been to her, And mentioned me to him:

She gave me a good character, But said I could not swim.

"He sent them word I had not gone (We know it to be true):

If she should push the matter on, What would become of you?

"I gave her one, they gave him two, You gave us three or more:

They all returned from him to you, Though they were mine before.

"If I or she should chance to be Involved in this affair,

He trusts to you to set them free Exactly as they were.

"My notion was that you had been (Before she had this fit) An obstacle that came between Him, and ourselves, and it. 

"Don't let him know she liked them best, For this must ever be A secret kept from all the rest, Between yourself and me."

"That's the most important piece of evidence we've heard yet," said the King, rubbing his hands; "so now let the jury-"

"If any one of them can explain it," said Alice (she had grown so large in the last few minutes that she wasn't a bit afraid of interrupting him), "I'll give him sixpence. I don't believe there's an atom of meaning in it."

The jury all wrote down on their slates, "She doesn't believe there's an atom of meaning in it," but none of them attempted to explain the paper.

"If there's no meaning in it," said the King, "that saves a world of trouble, you know, as we needn't try to find any. And yet I don't know," he went on, spreading out the verses on his knees and looking at them with one eye; "I seem to see some meaning in them after all; 'said I could not swim-'; you can't swim, can you?" he added, turning to the Knave.

The Knave shook his head sadly. "Do I look like it?" he said. (Which he certainly did not, being made entirely of cardboard.)

"All right, so far," said the King; and he went on muttering over the verses to himself:

" 'We know it to be true'-that's the jury, of course'If she should push the matter on'-that must be the Queen -What would become of you?' What indeed!-I gave him one, they gave him two!'-why that must be what he did with the tarts, you know-"

"But it goes on, 'They all returned from him to you,"," said Alice.

"Why, there they are!" said the King, triumphantly pointing to the tarts on the table. "Nothing can be clearer 
than that. Then again-'before she had this fit'-you never had fits, my dear, I think?" he said to the Queen.

"Never!" said the Queen, furiously, throwing an inkstand at the Lizard as she spoke. (The unfortunate little Bill had left off writing on his slate with one finger, as he found it made no mark; but he now hastily began again, using the ink that was trickling down his face, as long as it lasted.)

"Then the words don't fit you," said the King, looking round the court with a smile. There was a dead silence.

"It's a pun!" the King added in an angry tone, and everybody laughed. "Let the jury consider their verdict," the King said, for about the twentieth time that day.

"No, no!" said the Queen. "Sentence first-verdict afterward."

"Stuff and nonsense!" said Alice loudly. "The idea of having the sentence first!"

"Hold your tongue!" said the Queen, turning purple...

\section{APPENDIX $F$.}

A. A. W., p. 56 .

[Said the Pigeon to Alice:]...."No, no! You're a serpent; and there's no use denying it. I suppose you'll be telling me next that you never tasted an egg!"

"I have tasted eggs, certainly," said Alice, who was a very truthful child; "but little girls eat eggs quite as much as serpents do, you know."

"I don't believe it," said the Pigeon; "but if they do, why then they're a kind of serpent, that's all I can say"

This was such a new idea to Alice, that she was quite silent for a minute or two, which gave the Pigeon the opportunity of adding, "You're looking for eggs, I know that well enough; and what does it matter to me whether you're a little girl or a serpent?"

"It matters a good deal to me," said Alice hastily;.... 
APPENDIX G.

A. A. W., p. 106 .

"But why [asked Alice] did they live at the bottom of a well ?"

"Take some more tea," the March Hare said to Alice very earnestly.

"I've had nothing yet," Alice replied in an offended tone: "so I can't take more."

"You mean you can't take less," said the Hatter: "it's very easy to take more than nothing."

\section{APPENDIX $\mathrm{H}$.}

A. A. $W .$, p. 98.

"Then you should say what you mean," the March Hare went on.

"I do," Alice hastily replied; "at least-at least I mean what I say-that's the same thing, you know."

"Not the same thing a bit!" said the Hatter. "Why, you might just as well say that 'I see what I eat' is the same thing as 'I eat what I see.'"

"You might just as well say," added the March Hare, "that 'I like what I get' is the same thing as 'I get what I like'!"

"You might just as well say," added the Dormouse, which seemed to be talking in its sleep, "that 'I breathe when I sleep' is the same as 'I sleep when I breathe' !'

"It is the same thing with you," said the Hatter, and here the conversation dropped....

Fleet, England.

Philip E. B. Jourdain. 